\title{
Cuarta Revolución Industrial: las universidades y el papel de los investigadores
}

\author{
doi: $10.52749 /$ fh.v2i4.2
}

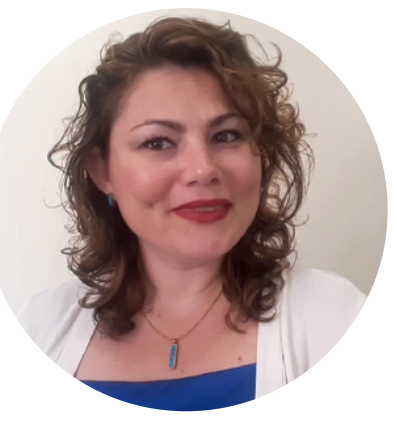

\section{CRISTIÁ LARA}

(iD) https://orcid.org/0000-0002-4037-3915

Máster en Estudios de Población (Universidad de La Habana, Cuba). Licenciada en Sociología (Universidad de Oriente, Cuba). Directora Académica en Asociación Iberoamericana de Sociología (AIS). Colaboradora en Organizaciones No Gubernamentales (ONGs). Docente e Investigadora. Escritora. Asesora independiente de tesis, monografías, metodologías y revisión de artículos científicos.

scristialara@gmail.com

Resumen. La Cuarta Revolución Industrial (4RI) es una revolución con toda una gestión masiva de datos, marcada por la digitalización de la información sobre las poblaciones y sus historias. El presente artículo ofrece elementos al debate en lo que respecta a la CRI, su vínculo con las universidades y el papel de los investigadores. Poner el conocimiento, innovación y tecnología en función de generar grandes beneficios es una oportunidad que no se debe desaprovechar. Los tiempos actuales demandan el fortalecimiento de habilidades. Permitámonos descubrir un mundo nuevo, crear redes globales con esencia en lo humano. ¿Apuestas por las oportunidades de la Cuarta Revolución Industrial (4RI)?

Palabras clave: Cuarta Revolución Industrial, investigadores, universidades

\section{Pinceladas acerca de la Cuarta Revolución Industrial (4RI)}

Desde hace algún tiempo se habla de Inteligencia Artificial (IA), Datos en la nube, Big Data, digitalización y otros términos que nos refieren y ubican -en mayor o menor medida- en la Cuarta Revolución Industrial (4RI); una revolución con toda una gestión masiva de datos, marcada por la digitalización de la información sobre las poblaciones y sus historias.

Alguna vez Ud. se ha preguntado ¿qué significa el término dato? El dato -según la Real Academia Española- es la información sobre algo concreto que permite su conocimiento exacto o sirve para deducir las consecuencias derivadas de un hecho. Es también, aquella información dispuesta de manera adecuada para su tratamiento por una computadora. De ahí que los datos sean poderosos, pues permiten conocer: ¿quiénes somos?, ¿qué nos caracteriza?, ¿cuáles son las necesidades sentidas, los deseos, las oportunidades?, ¿dónde estamos y hacia dónde queremos ir? por solo enunciar algunas interrogantes.

El presente artículo ofrece elementos al debate en lo que respecta a la $4 \mathrm{RI}$, su vínculo con las universidades y el papel de los investigadores. Destáquese que, si bien los cuestionamientos como: ¿quiénes colectan esos datos?, ¿qué métodos y técnicas de investigación se emplean para su recolección?, ¿se respetan los códigos éticos?, ¿qué tipo de gestión se hace con ese dato?, no son los únicos; son las interrogantes que motivaron a la autora a escribirlo. Quede claro, que se parte desde la perspectiva de que la 4RI es una oportunidad, más allá de los criterios que apuestan/avalan lo contrario. Siendo así, y en aras de adentrarnos en el tema, leamos la siguiente analogía.

Si nos enmarcamos en una investigación -desde las ciencias sociales-, los pasos serían: 1) contextualizar la situación problémica, 2) revisar el estado del arte, 3) identificar los métodos y técnicas a implementar -sea para un estudio exploratorio o para el desarrollo integral de la indagación científica-, 4) definir la muestra -seleccionar quiénes serían parte del estudio-, 5) aplicar las herramientas elegidas -cumpliendo con el código ético desde cada disciplina científica-, 6) procesar los datos levantados, y 7) elaborar el informe que expondrá los resultados, así como una serie de propuestas de acciones, cuyo fin es la disminución o erradicación de la situación problémica que dio lugar al desarrollo de la investigación.

Lo mismo ocurre en cada uno de los procesos/etapas de la 4RI: "La Era de la Información". Es un co- 
nocimiento científico, desde la ética humanista y fundamentada en valores. Esa información, ese dato levantado y gestionado -a través de diferentes metodologías y herramientas- para visualizar nuevos escenarios desde la digitalización y la secuencia cíclica: analizo-visualizo-acciono. Luego, surgen las diferentes propuestas.

Lo interesante de los datos es saber para qué lo preciso, cómo lo levanto, y qué hago con él. No es recolectar datos desaforadamente, todo debe tener sus porqués, e incluso se deben rediseñar las herramientas para un mejor levantamiento de lo que se desea -en caso que sea preciso-.

Poner el conocimiento, innovación y tecnología en función de generar grandes beneficios es una oportunidad que no se debe desaprovechar, solo se debe saber hacia dónde vamos y cuáles son los valores éticos que como científicos nos acompañan.

\section{Transferencia de conocimientos, fortalecimiento} de habilidades, acción y responsabilidad

Desde las universidades se genera y transfiere el conocimiento. Son las universidades el centro de la $4 \mathrm{RI}$, desde ellas se educa y forma el talento humano que registra y hace uso de los datos. Sin embargo, se precisa de nuevos estilos de formación, nuevas formas de ver los cambios que circundan a la humanidad y en el cual los procesos de socialización juegan un papel esencial en cuanto a la educación, formación, transmisión de valores y al ejercicio pleno de la ética profesional. Entiéndase, este último como las normas éticas que regulan las conductas morales del profesional, cualquiera sea la disciplina científica en la que se desempeñe.

Según Crovetto (2021) todo avance científico y tecnológico debe pasar por el filtro de la revisión ética para valorar sus efectos en la vida de los seres conscientes y el mundo en general, pero debemos reflexionar si el tener un colegio de profesionales y un curso de ética en la malla curricular de cualquier carrera garantizará que los egresados de dichas profesiones apliquen criterios éticos en su desempeño. Esta es una aspiración bastante ambiciosa, sin embargo, la opción de no desarrollar contenidos específicos relacionados a la ética en las propuestas educativas profesionales sería un camino mucho peor. Debemos de garantizar un mínimo de condiciones básicas de calidad educativa que aspire a la formación integral de los estudiantes.

En otro orden de ideas, es válido plantear que los tiempos actuales demandan el fortalecimiento de habilidades, la tecnología crece de forma expo- nencial; mientras que, el crecimiento en los seres humanos es lineal. Según Oppenheimer (2018, como se citó en Mori, 2021) las 10 áreas de trabajo del futuro serán: los asistentes de salud, los analistas de datos, ingenieros de datos y programadores, los policías digitales, los asesores de ventas, los cuidadores y programadores de robots, los profesores y maestros, los especialistas en energías alternativas, los artistas, deportistas y creadores de entretenimiento, los creadores y diseñadores de contenidos comerciales, y por último los consejeros espirituales.

Ahora bien, nos estará provocando Oppenheimer a reflexionar sobre si se está educando a la nueva generación de manera correcta para el mercado de las siguientes décadas o para los trabajos futuros que podrían surgir. Dado lo anterior, ¿qué cambios desde el plano personal te podrías estar proponiendo?, ¿qué habilidades deseas desarrollar?, son dos de las interrogantes que pudieras estar planteándote. Recuérdese, que antes de pretender un cambio colectivo, se debe iniciar por el cambio individual.

Asimismo, es menester apostar porque desde las diferentes profesiones se abogue e implemente la transdisciplinariedad, por la sistematización de saberes, por el uso de metodologías mixtas y de herramientas que permitan dar cuenta de los avances que desde la tecnología se están realizando en pos de poner el conocimiento en función de un mundo seguro, sano y justo.

Es responsabilidad de todos y a los diferentes niveles societales el velar por el bienestar de los seres humanos y de su adecuado desempeño y aprensión de habilidades en un mundo cada vez más digitalizado, sin poner en peligro el bienestar de las generaciones futuras. Resulta que raras veces nos detenemos a pensar o examinar que existe detrás de ese dato -a veces expuesto como una estadística más, como un número frío-; dato que da cuenta de la vida y dinámica de las poblaciones porque se es más que un número, no se es un dato alejado de sentimientos, emociones, criterio propio, pensamientos y expresión.

Si bien son humanos quienes diseñan la tecnología -porque antes de ser científicos, al nacer se les asignó esa condición humana- no es insólito cuestionarse reiteradamente ¿cómo hacer para que esta nueva tecnología contribuya al desarrollo sostenible e incluso del ser humano?, ¿hasta qué punto se considera a las personas, se piensa desde ellas?, ¿se contemplan los elementos sociales a la hora de diseñar?, ¿cuáles son los cuestionamientos 
que emergen a la hora de diseñar e implementar? cuando de tecnología, de digitalización y de 4RI hablamos.

Permitámonos descubrir un mundo nuevo, crear redes globales con esencia en lo humano, sin olvidar que todo proceso de cambio, de reajuste, rediseño y adaptación, expone en mayor medida las crisis con carácter asimétrico; pero si el fin último es lo que aglutina, todo podría ser superado a través de procesos de articulación y apoyo. Dar cierre a este set de incertidumbres desde la participación activa de todos los actores sociales, es el primer paso.

\section{Cuarta}

¿Apuestas por las oportunidades de la

Revolución Industrial (4RI)?

\section{Referencias}

Real Academia Española (RAE). Dato. https://dle.rae.es/dato Crovetto, A. (2021). La tecnoética: la importancia de enseñar ética en las carreras tecnológicas. Futuro Hoy, 2(1), 22-24. https://doi.org/10.52749/fh.v2i1.6

Mori, K. (2021). Inteligencia Artificial y sociedad ¿El fenómeno social tecnológico 4.0? Futuro Hoy, 2(1), 37- 41. https://doi.org/10.52749/fh.v2i1.11

\section{Cómo citar este artículo:}

Lara, C. (2021). Cuarta Revolución Industrial: las universidades y el papel de los investigadores. Futuro Hoy, 2(4), 14-16. https://doi.org/10.52749/fh.v2i4.2 